\title{
Female Concentration and the Adoption of Parental Leave in Japanese Work Organizations
}

\author{
Tetsushi FUJIMOTO \\ (Nanzan University)
}

\begin{abstract}
This study investigates the impact of female concentration on the implementation of parental leave policy by Japanese employers. Specifically, I examine how female ratio and the proportion of married women within firms affect Japanese employers' decisions about providing parental leave for their employees. I discuss how these employer characteristics are likely to be associated with the provision of family assistance based on theories of organizational behavior and test these hypotheses using data from 1779 business establishments in Japan. Findings indicate that firms with predominantly female workforces were not necessarily more likely to adopt parental leave. Surprisingly, the proportion of married women at the workplace exerted a powerful negative impact on employer adoption of parental leave, and this negative effect was significant across all levels of industrial female concentration. Results also show that the presence of a climate at work that discriminates against women tends to prevent the provision of parental leave. Interestingly, the proportion of women managers in a firm reduced the likelihood that parental leave is adopted by employers of large firms and heavily female industry.
\end{abstract}

\section{Introduction}

In this study, I explore employer characteristics that are associated with the implementation of parental leave policy in Japanese work organizations. Specifically, I address the following questions:

(1) How does female concentration within firms affect the adoption of parental leave by Japanese employers? Do female ratio and the ratio of married women increase the likelihood that parental leave is adopted in the firm?

(2) Do proportion female and the proportion of married women have different impacts on the adoption of parental leave for firms of different size and

An earlier version of this paper was presented at the 2000 annual meeting of the American Sociological Association in Washington, DC. The author gratefully acknowledges Naotaka Watanabe for his generous permission to use his data set for the present study. Direct all correspondence to Tetsushi Fujimoto, Department of Foreign Studies, Nanzan University, 18 Yamazato-cho, Showa-ku, Nagoya 466-8673 Japan. Phone 052-832-3111, ext.555.

e-mail: fujimoto@nanzan-u.ac.jp industry?

(3) How does workplace climate influence employer adoption of paid parental leave? Can the effect of female ratio on employer provision of parental leave be reduced to the differences in the levels of the sex discriminatory climate across firms?

In theory, employers provide family supportive policies to retain valuable employees with family responsibilities (cf. Lewis 1996; Marquart 1991; Tomita 1994). Employers in Japan, however, have been generally reluctant to provide family assistance for their employees, claiming that such policies, especially leave policies, would interfere with economic efficiency and hence with economic growth and productivity. Even when leave benefits are provided, in many cases they are provided without pay.

Although the Japanese government has been generally slow to respond to the needs of Japanese working parents torn between the competing demands of employment and family, it has slowly come to realize the importance of alleviating the stresses that working parents experience. The legislation of the Parental Leave Act of 1992 is an example of how 
the Japanese government has responded to the changing needs and demographic characteristics of the contemporary workforce in Japan. According to a study conducted in 1995, while $13 \%$ of Japanese employers that provided parental leave in 1995 had adopted the policy prior to the promulgation of the law in 1992, 49.5\% implemented the policy in the year the law was actually enforced. As this suggests, the Japanese Parental Leave Act of 1992 has exerted a powerful pressure on employers to provide family assistance for working parents in Japan. Though one could argue that the true intentions of those employers for implementing leave policy are just to abide by the law, but not necessarily to support women's career, and that many of Japanese employers might not have chosen to become "family-friendly" if the law had not been enforced, the fact is that those employers were forced to change their behaviors by the law, and there emerged a possibility that this forced behavioral modification could spark a change in the workplace attitudes towards women's employ. ment.

While prior studies have found that female concentration is an important determinant of employer provision of family responsive policies (Goodstein 1994; Osterman 1995; Seyer et al. 1995), past research on Japanese corporate family policies have failed to look at the impact of establishment-level female concentration on the implementation of family policies at work. Although we know that employer adoption of parental leave varies by industrial types, we can only speculate that industry-level female concentration may affect employers' policy provision. We still do not know how female concentration within establishments affects employer adoption of parental leave and whether the impact of establishment-level female concentration varies by firm size and industrial types.

Thus, this study investigates the relationship between employer provision of parental leave and female concentration within firms, and examines how the relationship is conditioned by the size and industry of firms.I examine whether the proportions of women and married women at work increases the likelihood that parental leave is adopted by an employer. I will also investigate how an employer's overall attitudes towards women's work affect the adoption of parental leave in Japanese work organizations.

\section{Theoretical Framework}

In this research, I draw on three conceptual models that provide analytic guidelines for employer provision of parental leave: the economic rationality model, the statistical discrimination model, and the model of gendered valuation. These conceptual models present different views on how workplace female ratio and organizational climate may affect employer provision of family assistance. Each model is briefly reviewed below.

\section{Economic Rationality Model}

Economic rationality explanations (cf. Becker 1964) of employer provision of family assistance emphasize the firm's rational attempt to reduce turnover and its associated costs in the expectation of generating higher productivity and enhancing competitiveness for the organization. As its core proposition, the model states that employers provide family responsive policies as a management strategy to maximize organizational profits and efficiency. Because women are more likely than men to be responsible for things such as household work and child care, those employers that hire a large number of women are likely to experience the routine problems of turnover, absenteeism, and lower worker commitment and productivity. Thus, the classic economic rationality model would suggest that firms with predominantly female workforces are more likely to respond to these problems by implementing family-supportive policies. Similarly, firms with married women would attempt to increase efficiency by implementing family-supportive policies.

\section{Statistical Discrimination Model}

It could be assumed that since implementation of family-responsive policies is expensive for employers, they would provide them only when it is certain that the implementation costs would be offset by the increased efficiency and reduced turnover among workers. In theory, employers will respond to workers' needs, as long as those workers are valuable 
assets for the organization. To attract and retain "good" employees, it is essential that employers offer what employees want. A key question, then, is who the "good" employees are for an employer. It may be argued that desired workers for an employer are not necessarily those productive employees who take advantage of family policies and stay with the firm, but rather "good citizens" who do not take advantage of expensive family policies. While employers take different workforce attributes into consideration when making decisions about whether or not to provide policies, statistical discrimination results when employers try to avoid policies that a larger percentage of the workforce would use by basing decisions on such information as female ratio and the proportion of married women in the workforce. Therefore, based on the economic logic of statistical discrimination, it is predicted that employers will become reluctant to provide policies when significant numbers of employees are women, especially married, precisely because they assume that their employees would actually use them.

Note, however, that industry-level female concentration also affects employer decisions about policy provision. In the case of firms operating in industries with predominantly female workforces, the retention of female labor is not a great concern since the replacement of female workers after the incident of turnover is much less costly in those industries. Rather than providing family support, it is economically more efficient for employers in predominantly female industries to segregate women in jobs where turnover costs and productivity concerns are minimal and then replace them when they leave the firm. In contrast, for firms in industries with a lower level of female concentration, it is more efficient to retain stable female workers, especially when the size of the firm is small. For those employers, statistical discrimination to exclude women is not a viable option. In this case, it may be a rational choice for an em. ployer to provide family policies to attract and retain female workers. Thus, the female concentration in labor markets is an important contextual factor for an employer's decisions about policy provision.

\section{Gendered Valuation Model}

Cultural feminism emphasizes the role of the devaluation of women and things typically associated with them in generating gender inequality. Kilbourne et al. (1994) offer a model of gendered valuation to provide a part explanation for gender pay inequality. The central proposition of the model is that cultural processes of valuation are gendered. This means that because women are devalued, social roles and traditionally female activities are culturally devalued relative to those associated with men. In general, societies devalue tasks and roles that are related to women (Shepela and Viviano 1984). Kilbourne et al. (1994) argue that if cultural values influence the type of jobs that employers value more, and such valuation is biased against jobs associated with women, we can predict that fewer benefits will be provided for those who are in predominantly female jobs than for those in predominantly male jobs.

Previously, this devaluation perspective has been used to explain the sex gap in occupational earnings. As studies show, the percentage of women in an occupation has a net negative impact on pay even after controlling for different types of qualifications and skills required for occupations (e.g., England 1992). One possible mechanism of such wage devaluation is that women's jobs are erroneously believed to require less effort than men's jobs, because efforts typically viewed as female are culturally invisible. "Once interoccupational wage differences are in place, institutional inertia keeps genderbased interjob wage difference in force (Kilbourne et al. 1994). Another possibility is that skills in lowwage occupations are devalued because they are usually carried out by women (Steinberg 1990). An example of a skill typically associated with women is nurturant skill (e.g., skills required in face-to-face customer service, or care-providing work such as nursing). Such skills are viewed as female because of their "relationship to the nurturant behavior entailed in parenting, done primarily by women, and because nurturant paid jobs are usually filled by women" (Kilbourne et al. 1994).

In view of the bottom-line logic of cultural feminism that jobs associated with women are devalued 
because women do them, it may be predicted that employers minimize any employee benefits when a workplace is predominantly female. Employers could see women workers as replaceable labor of low value, and therefore it is unlikely that they will be concerned with the retention of their female employees.

\section{Summary of Conceptual Models}

As the above review shows, the economic rationality model, the statistical discrimination model, and the gendered valuation model present differing views on how employers might provide family policies for their employees. The arguments drawn from these conceptual models can be summarized as follows. First, the key concept of the economic rationality model is efficiency. According to the pure rationality argument, it is efficient for employers of a firm with predominantly female workforces to provide family-supportive policies, because it reduces turnover among women and thus enhances organizational efficiency. The model's assumption is that women would remain with the firm and work productively if policies that facilitate integrating work and their family lives become available. In the present study, this means that the proportion women at the workplace and the presence of familysupportive policies should be positively associated. Particularly in a workplace where the proportion of married women is high, family benefits are likely to be provided, reflecting their stronger need for balancing work and the family. Thus, the proportion married among female employees in a workplace and the presence of family-supportive policies should be positively related.

Based on the logic of statistical discrimination, one could argue that it is economically inefficient for employers of firms with predominantly female workforces to provide family-supportive policies, because women who assume domestic responsibilities would use them, and therefore it adds more economic costs for the employer. Drawing on this argument, it is predicted that female ratio in the workplace and the presence of family-supportive policies should be negatively associated. Similarly, the proportion of married women in a workplace should be negatively associated with the presence of family-supportive policies.

Firm size and industry-level female concentration, however, must be integrated in the statistical discrimination perspective on employers' efficiency concerns. Employers of large, resourceful firms or those operating in female-dominant industries would choose not to provide family assistance, because given their economic resources, and cheaper, plentiful female workers in their industrial labor markets, it is economically more efficient to replace women when they leave the firm. In contrast, employers of micro and small-sized firms, or firms operating in industries with a lower level of female concentration would choose to provide family policies to attract and retain female workers, because the costs for replacing women could be more expensive than implementing family policies in those industries. Thus, the effects of firm size and the business operation in female-dominant industries on the adoption of parental leave would be negative, and the negative effect of female ratio would be stronger in larger firms and female-dominant industries.

In stark contrast to the assertions of economic efficiency, it is argued in the cultural feminist model of gendered valuation that when the rate of female concentration is high in a workplace, the jobs performed by women are likely to be devalued. Employers running predominantly female workplaces would label their employees as less valuable as a replaceable workforce, so that it is unlikely that retention of their employees would become a concern for them. Therefore, those employers would not consider providing family assistance for their employees. Thus, if the gendered valuation arguments hold, the relationship between female ratio in the workplace and the presence of parental leave would be negative.

In a work organization, the way an employer values its employees may be reflected in the workplace climate. When the general climate at work devalues female labor, it may directly prevent the implementation of family-supportive policies in the workplace.

This view tacitly assumes that those in executive and managerial positions who are likely to be involved in the formation of a workplace climate, are mainly men. As Kanter (1977) suggests, a relative 
Female Concentration and the Adoption of Parental Leave in Japanese Work Organizations

absence of women in the middle and upper levels of management can create a negative impression that discourages women from attempting to better themselves within the organization. If women are in those higher ranks, however, it is possible that the level of female devaluation would be lower and women's family needs would be more reflected in employment policies, and therefore family assistance would be more likely to be provided.

Indeed, female concentration within firms may be closely associated with the degree to which employment practices at work is sex discriminatory. It may be that workplace climates tend to be less sex discriminatory and that women are more likely to be promoted to managerial positions in workplaces where female ratio is high, and this less discriminatory climate, rather than proportion of women in the workplace as such, may increase the likelihood that family assistance is provided.

Thus, if the assertion of the gendered valuation model holds, the relationship between a workplace climate that devalues women and the presence of parental leave would be negative, whereas the relationship between the number of female managers at work and the provision of parental leave would be positive. Furthermore, the effects of proportion female and proportion married among women would turn statistically insignificant when workplace climate and the number of women managers are controlled.

\section{Methods}

\section{Data}

The data used in this study come from a survey conducted in June 1992 among 3000 business establishments in Aichi Prefecture, Japan. Questionnaires were mailed to the personnel departments at these establishment. Out of 3000 questionnaires mailed, 1779 were returned directly to the investigator (response rate 59.3\%). The questions measured the characteristics of the establishment and aspects of the resource management of female employees. The distribution of industries among the respondents was as follows: construction $15.8 \%$, manufacturing 33.4 $\%$, electric, gas, and water services $1.3 \%$, transportation and communications $8.4 \%$, wholesale, retail and food supply $19.5 \%$, banking and insurance $2.6 \%$, real estate $2.8 \%$, service $10.2 \%$, other $5.9 \%$.

\section{Measures}

\section{Dependent Variable: Presence of Parental Leave}

The presence of parental leave in an establishment was measured by asking personnel departments whether it was provided by their establishments, or whether its provision was under consideration, or whether it was neither provided nor being considered at the time of the survey. For the present analysis, I combined the second and the third response categories so that the parental leave variable indicates whether an employer has adopted parental leave in an establishment or not $(1=$ provided, $0=$ not provided).

Independent Variables: Organizational Characteristics

Firm size was measured by the number of employees in an establishment.

Women's Average Length of Employment in the Establishment was tapped by the average number of years of women's employment at each establishment.

Number of Female Part-time Workers was measured by a count of female part-time employees in each establishment.

Number of Married Full-time Women was measured by a count of married women employees in each establishment.

Proportion of Women was measured by dividing the number of full-time female employees by the total number of employees in each establishment.

Proportion of Married Women was measured by dividing the number of married full-time female employees by the total number of female employees in each establishment.

Industry-level Female Concentration was categorized into the following three levels using governmental labor statistics from 1992:

(1) High-level concentration industries (approximately $50 \%$ female, $1=$ retail, wholesale, food supply, real estate, banking, insurance, and service industries, $0=$ other)

(2) Mid-level concentration industry (approximately $35 \%$ female, $1=$ manufacturing, $0=$ other)

(3) Low-level concentration industries (approxi- 
mately $17 \%$ female, $1=$ construction, electric, gas, water supply, transportation, $0=$ other).

In logistic regression analysis, high-level industry was used as a reference category.

Number of Women Managers was measured by summing the number of women in managerial positions in each establishment.

Proportion of Women Managers was measured by dividing the number of women managers by the total number of full-time female employees in each establishment.

Sex Discriminatory Workplace Climate is the extent to which sex discriminatory employment practices are present at the workplace. It was measured by a scale which is the unweighted average of 9 five-point Likert format indexes: "There are a number of opportunities for women to try different things here." "Women are provided with a sufficient amount of job training here." "Women are treated well here." (coded as $5=$ strongly disagree, $1=$ strongly agree) "Women are not promoted here." "Women cannot work until retirement here." "This company is wasting women's abilities." "Sexual harassment exists here." "There are pay gaps between men and women here." "Women are responsible for chores like serving tea and cleaning here." (coded as $5=$ strongly agree, $1=$ strongly disagree). The internal reliability of the discriminatory workplace climate scale was .754 .

\section{Statistical Procedure}

Statistical data analysis consisted of a sequence of logistic regressions. The regression models to be estimated employed the presence of parental leave at work as a dependent variable. Initially, the presence of parental leave was regressed on firm size, number of married full-time women, number of female parttime workers, women's average length of employment at work, proportion of women at work, proportion of married women, and industry-level female concentration (Model 1). Then, in the following model, sex discriminatory workplace climate and the number and proportion of women managers were additionally entered into the equation (Model 2). After estimating models 1 and 2 with an aggregate sample, model 2 was estimated by stratifying the sample into three levels of firm size and three levels of industrial female concentration

\section{Results}

Table 1 presents the means and standard deviations of variables in the analysis. As the results show, approximately $27 \%$ of employers in the present sample currently provide parental leave for their employees, while $30.3 \%$ of employers were considering adopting parental leave (result not reported). The relatively high percentage of employers either providing or considering adopting parental leave may be due to the fact that the Parental Leave Act was enforced in the spring of 1992, and that the present workplace survey was conducted in June of the same year.

The results show that larger firms are more likely to adopt parental leave. While $73 \%$ of the large establishments hiring more than 300 employees had adopted parental leave prior to the promulgation of the Parental Leave Act, only $17 \%$ of small establishments hiring less than 100 employees had provided leave. It is also indicated that there is a significant gap in the employer adoption of parental leave across industries. Industries hiring a smaller proportion of women are less likely to adopt parental leave. Only $18 \%$ of employers in low female concentration industries (construction, electric, gas, water supply, $\&$ transportation) provided leave, whereas $42 \%$ of employers in mid level concentration category (manufacturing) and $32 \%$ of those in high concentration category (retail, wholesale, food supply, real estate, banking, insurance, and service) provided leave.

Table 2 reports the results of logistic regression of parental leave on organizational characteristics using an aggregate sample of establishments. The result obtained from Model 1 regression shows that while the effect of the proportion of married women is negative $(b=-1.195, p<.001)$, the effect of the actual number of married full-time women is positive $(b=2.171, p<.001)$. These effects remained strong and statistically significant even after controlling for sex discriminatory workplace climate and the number and the proportion of women managers in Model 2 . This means that when other organizational characteristics are held constant across sample establish- 
Table 1 Means and Standard Deviations for Varhables in Analysis

\begin{tabular}{|c|c|c|}
\hline & Mean & $\begin{array}{l}\text { Standard } \\
\text { Deviation }\end{array}$ \\
\hline \multicolumn{3}{|l|}{ Dependent Variable } \\
\hline Parental Leave $(1=$ provided, $0=$ not provided $)$ & .266 & .442 \\
\hline \multicolumn{3}{|l|}{ Parental Leave by Firm Size } \\
\hline Small (less than 100) & .17 & .379 \\
\hline Medium $(100-300)$ & .38 & .486 \\
\hline Large (more than 300 ) & .73 & .444 \\
\hline \multicolumn{3}{|l|}{ Parental Leave by Indnstrial Female Concentration } \\
\hline High (retail, wholesale, food supply, real estate, banking, insurance, \& service) & .32 & .469 \\
\hline Middle (manufacturing) & .42 & .495 \\
\hline Low (construction, electric, gas, water supply, \& transportation) & .18 & .381 \\
\hline \multicolumn{3}{|l|}{ Independent Variables } \\
\hline Firm Size & 276.979 & 1475.734 \\
\hline Women's Average Length of Employment in the Establishment & 9.667 & 9.258 \\
\hline Number of Female Part-Time Workers & 15.076 & 73.860 \\
\hline Number of Married Full-Time Women & 28.132 & 84.942 \\
\hline Number of Women Managers & 2.889 & 10.321 \\
\hline \multicolumn{3}{|l|}{ High-Level Female Concentration Industry } \\
\hline $\begin{array}{l}(1=\text { retail, wholesale, food supply, real estate, banking, insurance, } \\
\text { and service; } 0=\text { other })\end{array}$ & .310 & .463 \\
\hline Mid-Level Female Concentration Industry $(1=$ manufacturing, $0=$ other $)$ & .161 & .368 \\
\hline $\begin{array}{l}\text { Low-Level Female Concentration Industry }(1=\text { construction, electric, gas, } \\
\text { water supply, and transportation; } 0=\text { other })\end{array}$ & .234 & .424 \\
\hline Proportion of Women to Full-Time Workers & .283 & .214 \\
\hline Proportion of Married Women to Full-Time Workers & .441 & .338 \\
\hline Proportion of Women Managers to Full-Time Workers & .128 & .219 \\
\hline Sex Discriminatory Workplace Climate (1-5) & 2.592 & .635 \\
\hline
\end{tabular}

ments, the more an employer hires married women (who are presumably burdened with more family responsibilities), the more likely it is that they adopt parental leave, but along with the increase in the relative size of married women to all full-time women in the firm, the adoption of parental leave becomes less likely. Caution is necessary, however, when interpreting these results. Married women employed in establishments in the present sample may not necessarily be in their child-rearing age. It is possible that these married women sought that employment after they had finished their child-rearing responsibilities. If this is the case, it is not surprising that the percentage married among women is negatively associated with the provision of parental leave.
The result from Model 2 regression in Table 2 shows that sex discriminatory workplace climate negatively affects employer provision of family policies, and this result supports the hypothesis formulated on the basis of the gendered valuation argument. It is interesting to note that while the actual number of women managers is likely to increase the likelihood of policy provision, the relative size of women managers to full-time women is negatively associated with adoption of the policy.

When the results from Models 1 and 2 are compared, it shows that the size of the regression coefficient for the proportion of married women did not change significantly between the two models. This means that differences in policy provision across 
Table 2 Logistic Regression Coefficients for Regression of Employer Adoption of Parental Leave on Selected Independent Variables: Aggregate Sample

\begin{tabular}{|c|c|c|}
\hline Independent Variables & Model 1 & Model 2 \\
\hline \multirow[t]{2}{*}{ Firm Size/100 } & $.304-$ & $.274=$ \\
\hline & $(.046)$ & $(.47)$ \\
\hline \multirow[t]{2}{*}{ Women's Average Length of Employment } & $.012^{\dagger}$ & $.013^{*}$ \\
\hline & $(.007)$ & $(.007)$ \\
\hline \multirow[t]{2}{*}{ Number of Female Part-Time Workers/100 } & $-.325^{* *}$ & $-.300^{*}$ \\
\hline & $(.114)$ & $(.112)$ \\
\hline \multirow[t]{2}{*}{ Number of Married Full-Time Women/100 } & $2.171^{-}$ & $2.015^{-}$ \\
\hline & $(.494)$ & $(.528)$ \\
\hline \multirow[t]{2}{*}{ Proportion of Women to Full-Time Workers } & -.209 & -.623 \\
\hline & $(.260)$ & $(.381)$ \\
\hline \multirow[t]{2}{*}{ Proportion of Married Women to Full-Time Women } & $-1.195^{\cdots *}$ & -1.055 \\
\hline & $(.241)$ & $(.249)$ \\
\hline \multirow[t]{2}{*}{ Mid-Level Female Concentration Industry } & .207 & .267 \\
\hline & $(.172)$ & $(.175)$ \\
\hline \multirow[t]{2}{*}{ Low-Level Female Concentration Indussry } & $-.585^{*}$ & $-.522 *$ \\
\hline & $(.187)$ & $(.192)$ \\
\hline \multirow[t]{2}{*}{ Sex Discriminatory Workplace Climate } & - & $-.556^{-}$ \\
\hline & & $(.108)$ \\
\hline \multirow[t]{2}{*}{ Number of Women Managers } & - & $.025^{*}$ \\
\hline & & $(.011)$ \\
\hline \multirow[t]{2}{*}{ Proportion of Women Managers to Full-Time Women } & - & -.341 \\
\hline & & $(.218)$ \\
\hline-2 Log Likelihood/df & $1496.818 / 1566$ & $1463.430 / 1563$ \\
\hline $\mathrm{N}$ & 1575 & 1575 \\
\hline
\end{tabular}

Note: Numbers in parentheses are standard errors.

establishments with various concentration levels of married women cannot be explained by the differences in the degree of sex discrimination. Similarly, the size of the regression coefficient for firm size changed only slightly between Models 1 and 2. This implies that, regardless of workplace climate, the availability of resources affects an employer's adoption of parental leave and, further, that the availability may vary across firms of different sizes.

Table 3 reports the results of logistic regression of parental leave, performed with samples stratified into three firm size categories. Although the effect of the proportion of married women is negative in all three models, the effect is strong and statistically significant particularly for medium-sized firms hiring 100 to 300 employees $(b=-1.274, p<.05)$. This suggests that it is in this medium-size category that the concentration of married women within firms reduces the likelihood that parental leave is adopted by an employer.

While firm size increased the likelihood of policy provision for both small-sized firms hiring less than 100 employees and medium-sized firms hiring 100 to 300 employees, the impact of firm size was stronger for small-sized firms. Also, the negative effect of sex discriminatory workplace climate was stronger in small-sized firms. The effect of the proportion of women managers on the adoption of parental leave, however, was negative in all three models, but the effect was most powerful for large firms hiring more than 300 employees.

The results of logistic regression of parental leave, performed with samples stratified by the level of industrial female concentration are reported in Table 
Female Concentration and the Adoption of Parental Leave in Japanese Work Organizations

Table 3 Logistic Regression Coefficients for Regression of Employer Adoption of Parental Leave on Selected Independent Variables: Three Levels of Firm Size

\begin{tabular}{|c|c|c|c|}
\hline \multirow[b]{2}{*}{ Independent Variables } & \multicolumn{3}{|c|}{ Firm Size } \\
\hline & $\begin{array}{c}\text { Small } \\
\text { Less than } 100 \\
(\mathrm{~N}=996)\end{array}$ & $\begin{array}{l}\text { Medium } \\
100-300 \\
(\mathrm{~N}=351)\end{array}$ & $\begin{array}{c}\text { Large } \\
\text { More than } 200 \\
(\mathrm{~N}=228)\end{array}$ \\
\hline \multirow[t]{2}{*}{ Firm Size/100 } & $1.046^{*}$ & $.525^{*}$ & .083 \\
\hline & $(.509)$ & $(.234)$ & $(.055)$ \\
\hline \multirow[t]{2}{*}{ Women's Average Length of Employment } & $.016^{\dagger}$ & .007 & $.073^{\dagger}$ \\
\hline & $(.009)$ & $(.014)$ & $(.041)$ \\
\hline \multirow[t]{2}{*}{ Number of Female Part-Time Workers/100 } & $-5.011^{*}$ & -.233 & -.110 \\
\hline & $(1.951)$ & $(.444)$ & $(.102)$ \\
\hline \multirow[t]{2}{*}{ Number of Married Full-Time Women/100 } & 2.204 & .260 & 1.030 \\
\hline & $(2.523)$ & $(1.216)$ & $(.950)$ \\
\hline \multirow[t]{2}{*}{ Proportion of Women to Full-Time Workers } & -.931 & 1.342 & -.006 \\
\hline & $(.658)$ & $(.932)$ & $(1.760)$ \\
\hline \multirow[t]{2}{*}{ Proportion of Married Women to Full-Time Women } & -.261 & $-1.274^{*}$ & -.971 \\
\hline & $(.367)$ & $(.630)$ & $(1.252)$ \\
\hline \multirow[t]{2}{*}{ Mid-Level Female Concentration Industry } & -.215 & $.792 *$ & .337 \\
\hline & $(.282)$ & $(.301)$ & $(.455)$ \\
\hline \multirow{2}{*}{ Low-Level Female Concentration Industry } & $-.731^{*}$ & -.203 & -.338 \\
\hline & $(.264)$ & $(.598)$ & $(.503)$ \\
\hline \multirow[t]{2}{*}{ Sex Discriminatory Workplace Climate } & $-.694 *$ & $-.380^{*}$ & -.313 \\
\hline & $(.160)$ & $(.185)$ & $(.291)$ \\
\hline \multirow[t]{2}{*}{ Number of Women Managers } & $.075^{+}$ & .010 & .061 \\
\hline & $(.044)$ & $(.013)$ & $(.038)$ \\
\hline \multirow[t]{2}{*}{ Proportion of Women Managers to Full-Time Women } & -.330 & -.003 & $-5.230^{\dagger}$ \\
\hline & $(.335)$ & $(.281)$ & $(3.135)$ \\
\hline-2 Log Likelihood/df & $765.167 / 984$ & $421.192 / 339$ & $211.212 / 216$ \\
\hline
\end{tabular}

${ }^{\dagger} \mathrm{p}<.10 ; \quad$ " $\mathrm{p}<.05 ; \quad \mathrm{p}<.01, \quad \mathrm{p}<.001$

Note : Numbers in parentheses are standard errors.

4. The results indicate that a proportion of women reduces the likelihood of policy provision for midlevel concentration industry (i.e., manufacturing), whereas proportion of married women reduces the likelihood irrespective of the level of industrial female concentration. Interestingly, the positive effect of the number of married full-time women was most powerful for firms operating business within industries of low-level concentration $(b=13.641$, $\mathrm{p}<.001)$. For these firms, the effect of a proportion of married women was relatively small and statistically significant only at a marginal level $(b=-.975$, $\mathrm{p}<.10$ ). Therefore, the results imply that for firms in industries of low-level female concentration (i.e., construction, electric, gas, water supply, and transportation industries), the actual number of married women, rather than their proportion, is particularly an important determinant of whether parental leave is adopted.

\section{Conclusion}

The present results suggest that a simple increase in the number of women in need of family assistance at work does not necessarily lead to the adoption of parental leave by employers in Japan. Results from the statistical analysis of data failed to support the pure economic rationality argument that firms with predominantly female workforces provide family assistance because it enhances organizational efficiency. Instead, the results indicated that employers are unlikely to provide family assistance even when a large proportion of female employees are married 
Table 4 Logistic Regression Coefficients for Regression of Employer Adoption of Parental Leave on Selected Independent Variables: Three Industrial Female Concentration Levels

\begin{tabular}{|c|c|c|c|}
\hline \multirow[b]{2}{*}{ Independent Variables } & \multicolumn{3}{|c|}{ Industrial Female Concentration } \\
\hline & $\begin{array}{c}\text { High } \\
(\mathrm{N}=511)\end{array}$ & $\begin{array}{c}\text { Middle } \\
(\mathrm{N}=273)\end{array}$ & $\begin{array}{c}\text { Low } \\
(\mathrm{N}=368)\end{array}$ \\
\hline \multirow[t]{2}{*}{ Firm Size/100 } & $.212^{* *}$ & .069 & $.169^{\dagger}$ \\
\hline & $(.075)$ & $(.081)$ & $(.098)$ \\
\hline \multirow[t]{2}{*}{ Women's Average Length of Employment } & $.048^{-*}$ & -.005 & -.012 \\
\hline & $(.014)$ & $(.015)$ & $(.019)$ \\
\hline \multirow[t]{2}{*}{ Number of Female Part-Time Workers $/ 100$} & -.187 & .132 & $-4.199^{\dagger}$ \\
\hline & $(.192)$ & $(.573)$ & $(2.365)$ \\
\hline \multirow[t]{2}{*}{ Number of Married Full-Time Women/100 } & $1.393^{\dagger}$ & $2.623^{*}$ & $13.641-$ \\
\hline & $(.775)$ & $(1.107)$ & $(4.358)$ \\
\hline \multirow{2}{*}{ Proportion of Women to Full-Time Workers } & -.020 & $-2.111^{*}$ & -.973 \\
\hline & $(.270)$ & $(1.029)$ & $(1.558)$ \\
\hline \multirow[t]{2}{*}{ Proportion of Married Women to Full-Time Women } & $-1.001^{*}$ & $-2.017^{* *}$ & $-.975^{\dagger}$ \\
\hline & $(.469)$ & $(.585)$ & $(.549)$ \\
\hline \multirow[t]{2}{*}{ Sex Discriminatory Workplace Climate } & $-.496 \cdots$ & $-.647^{*}$ & $-.879^{*}$ \\
\hline & $(.178)$ & $(.257)$ & $(.290)$ \\
\hline \multirow[t]{2}{*}{ Number of Women Managers } & $.056 *$ & .051 & -.036 \\
\hline & $(.021)$ & $(.043)$ & $(.042)$ \\
\hline \multirow[t]{2}{*}{ Proportion of Women Managers to Full-Time Women } & $-1.633^{*}$ & -.634 & .429 \\
\hline & $(.815)$ & $(.708)$ & $(.330)$ \\
\hline-2 Log Likelihood/df & $498.198 / 501$ & $266.762 / 263$ & $251.769 / 358$ \\
\hline
\end{tabular}

${ }^{\dagger} \mathrm{p}<.10 ; \quad$ " $\mathrm{p}<.05 ; \quad \mathrm{p}<.01, \quad \mathrm{p}<.001$

Note: Numbers in parentheses are standard errors.

High = retail, wholesale, food supply, real estate, banking, insurance, and service industries

Mid $=$ manufacturing industry

Low $=$ construction, electric, gas, water supply, and transportation industries

and in need of support from their employers. This may be interpreted as meaning that employers statistically discriminate against women who are likely to use family policies to continue employment, and thus the employers intentionally avoid implementing expensive policies. The negative effect of the proportion of married women was significant across all levels of industrial female concentration.

Given these results, there remains a possibility that many Japanese employers decided to adopt parental leave in order to abide by the Parental Leave Act of 1992, and that they did not necessarily intend to support women's career development by facilitating their continued employment with the leave. After all, implementation of parental leave policy in the workplace does not automatically mean that employees would use it, and thus policy adoption by itself may not be a good indicator of employer's "family friendli- ness" or serious attitudes towards women's career.

This research also revealed that the presence of a climate at work that discriminates against women and devalues female labor tends to prevent the provision of parental leave. The results, however, have shown that the proportion of women managers does not necessarily increase the likelihood that parental leave is adopted by the employer. Thus, the results provided mixed support for the hypothesis drawn from the cultural feminist model of gendered valuation. It is worth noting here the relationship between workplace climate and women's promotion to managerial positions. In the present sample, sex discriminatory climate and the number of women managers were only weakly correlated $(r=-.098$, $\mathrm{p}<.05$ ), and the correlation between climate and the proportion of managers to all full time women was not even statistically significant $(r=-.035)$. This 
Female Concentration and the Adoption of Parental Leave in Japanese Work Organizations

means that climate at work has little to do with employer decisions of promoting women to managerial positions, and that even in the workplace where climate is not particularly discriminatory against women, the likelihood of women's promotion is still small. Thus, the number or proportion of women managers in establishment may not be the most appropriate indicator of employer sensitivity to gender equality at work. Given this, one possible interpretation of why the ratio of women managers exerted a negative effect on policy adoption is that large employers and those in female-concentrated industries tend to be placed under environmental pressure for accommodating their employment practices to societal expectations for gender equality, simply because they are socially salient but not because they are truly willing to support women's career. Therefore, they promote women to managerial positions (perhaps to lower level) as a "gesture", yet they remain indifferent to providing further assistance, such as parental leave, for their female employees to develop their career.

While differences in the level of sex discrimination between sample establishments could not explain why the proportion of married women reduced the likelihood of employer adoption of parental leave, sex discriminatory workplace climate remains as an important barrier to policy provision. As long as sex discriminatory climate is present at work, Japanese employers are unlikely to provide family assistance for their employees, no matter what the sex composition of their workforces may be. The fact that sex discriminatory workplace climate exerts a powerful negative influence on employer provision of family policies presents an important agenda for future research on Japanese economic organizations and women's work. It is highly likely that workplace climate affects not only the provision of policy itself but also employees' access to the policy implemented by their employers. Since organizational climate shapes employment conditions for women, the question that must be answered is how we can change sex discriminatory culture in the workplace.

\section{References}

Becker, G. S. 1964 Human capital: $A$ theoretical and empirical analysis with special reference to education. New York: National Bureau of Economic Research.

England, P. 1992 Comparable worth: Theories and evidence. Hawthorn, N.Y.: Aldine de Gruyter.

Goodstein, J. D. 1994 Institutional pressures and strategic responsiveness: Employer involvement in work-family issues. Academy of Management Journal, 37, 350-82.

Kanter, R. M. 1977 Men and women of the corporation. New York: Basic Books.

Kilbourne, B. S., Farkas, G., Beron, K., Weir, D., and England, P. 1994 Returns to skill, compensating differentials, and gender bias: Effects of occupational characteristics on the wages of white women and men. American Journal of Sociology, 100, 689-719.

Lewis, S. 1996 Rethinking employment: An organizational culture change framework. In S. Lewis and J. Lewis, (Eds.) The work-family challenge: Rethinking employment. London: Sage Publications. 1-19.

Marquart, J. M. 1991 How does the employer benefit from child care? In J.S. Hyde and M.J. Essex, (Eds.) Parental leave and child care: Setting a research and policy agenda, Philadelphia: Temple University Press. 229-245.

Osterman, P. 1995 Work/family programs and the employment relationship. Administratice Science Quarterly, 40, 681-700.

Seyer, D. L., Monroe, P. A., and Garan, J.C. 1995 Balancing work and family: The role of employer-supported child care benefits. Journal of Family Issues, 16, 170-93.

Shepela, S. T., and Viviano, A.T. 1984 Some psychological factors affecting job segregation and wages. In H. Remick, (Ed.) Comparable worth and wage discrimination, Philadelphia: Temple University Press. 47-58.

Steinberg, R. J. 1990 Social construction of skill: Gender, power, and comparable worth. Work and Occupations, 17, 449-82.

Tomita, Y. 1994 Josei no Jinzai Ikusei kara mita 
Ikuji Kyugyo Seido (Parental leave from the perspective of female personnel development). In K. Muramatsu. (Ed.) Stokku Chousei ka no Koyou to Roudouryoku Bunpai, Kansai Economic
Research Center.

Received October 10, 2001 Accepted April 5, 2002 